\title{
Virtual Platforms in Social Networking Sites for Climate Change Education
}

\author{
Hasan Aydin \\ College of Education, Curriculum \& Instruction Department \\ Yildiz Technical University, Istanbul, Turkey \\ E-mail: aydinh@yildiz.edu.tr
}

Md. Mokter Hossain

College of Education, University of Nevada, Reno

E-mail: $\underline{\text { mokter@gmail.com }}$

Accepted: May 25, 2012 Published: June 20, 2012

Doi:10.5296/ijld.v2i3.1973 URL: http://dx.doi.org/10.5296/ijld.v2i3.1973

\begin{abstract}
Due to the aberrant nature of global weather in recent years, climate change has become an important issue in the national and international forums. This paper discusses a way of building intercultural virtual platforms in the social networking sites to coordinate the secondary school students and teachers from diverse corners of the world on a common platform where they can disseminate their voices on climate change issues.
\end{abstract}

Keywords: Social networking, Climate change education, and Global warming

\section{Introduction}

Today, the climate change is a vital issue that has been focused on by individuals, government and non-government organizations worldwide. Due to the aberrant nature of global weather in recent years, people are now more anxious about the earth's condition for future generations. Governments and organizations from various countries, especially those which are affected by the global warming issues have brought up climate change issues to the United Nations and other concerned agencies to protect them from the possible disasters related to climate change. That movement has forced the world leaders to think and talk about the global warming, climate change, and environmental pollution issues. Thus, the global warming and climate change issues have become important topics in national and international 
forums. There is a potential to coordinate the secondary school students and teachers from diverse corners of the world on a common platform (via Internet) where they can publicize their voices on global warming and climate change issues.

One of the best ways of making people be aware of climate change issues is using the advanced features of social networking and communication technologies. Social networking applications such as Facebook, twitter, hi5, and MySpace are emerging technologies that could be used to build many virtual societies. Social networking brings students and teachers of a school, or school district, together in order to share their perspectives about global warming, environmental pollution, and climate change. Based on the advanced and interactive features of Facebook technology, it could be an appropriate medium to build virtual forums at home and abroad. Such virtual forums would allow students from local and/or diverse cultures and societies in a single platform to let them discuss about the possible effects of environmental pollution, global warming, and climate change, and help them work together against these issues.

\section{Background of the Study}

The weather represents the current statistics of temperature, wind, rainfall, humidity, atmospheric pressure, atmospheric particle count, and some other meteorological elements of a certain area or region. In contrast, the climate refers to the average weather conditions of that area or region over a long period of time, ranging from three to four decades (Wikipedia, 2011). Thus, climate change refers to the long-term change in the ${ }^{1}$ average weather conditions or statistical distribution of weather patterns over a period that ranges from several decades to thousands or millions of years (Houghton, 2001). It may be a change in the average weather conditions or a change in the distribution of weather events with respect to an average; for example, fewer or greater extreme weather events. Climate change may also be limited to a specific region, or may occur across the whole Earth.

Evidence says that the increase of global temperature is the main cause of climate change, and that is happening due to the excessive release of gases such as $\mathrm{CO}_{2}, \mathrm{CH}_{4}, \mathrm{CFCs}$, $\mathrm{N}_{2} \mathrm{O}$, and $\mathrm{O}_{3}$ into the Earth's atmosphere (Ulukan, 2009). These gases are considered the main factors of global warming as these affect the interaction between the first and the second atmospheric layers of the Earth (troposphere and stratosphere respectively) by preventing the reflection of solar rays (IPCC, 2007; Ulukan, 2009). Increasing temperature, irregularities in rain, flood, drought, decreasing underground water levels, shorter or longer range of seasons, changing precipitation patterns, reducing snow cover, changing soil moisture, melting sea ice and glaciers, raising sea-water level, earlier flowering and ripening of flowers and fruits, and migration of plants and animals towards the poles, are the visual signs of global warming (Bates, Kundzewicz, Wu, \& Palutikof, 2008; Ulukan, 2009). The factors are just part of the problem. There are also non-visible issues.

According to the 2007 Fourth Assessment Report by the Intergovernmental Panel on Climate Change (IPCC), the average temperature of the Earth's near-surface air and oceans has been increased $0.74 \pm 0.18{ }^{\circ} \mathrm{C}\left(1.33 \pm 0.32{ }^{\circ} \mathrm{F}\right)$ during the $20^{\text {th }}$ century, and is projected to be continued in the $21^{\text {st }}$ century (IPCC, 2007). According to the United States National Academy 
of Sciences [USNAS], most of the observed temperature increase in the last half of the $20^{\text {th }}$ century, has been caused primarily by human activities that have increased the amount of greenhouse gases in the atmosphere including excessive burning of fossil fuel, and deforestation (USNAS, 2008). As the developed and industrialized countries use a large portion of fossil fuel and natural energy, they are considered as mostly responsible for global warming because although there are international agreements e.g., 1997- Kyoto Protocol, to limit these undesirable and dangerous developments, there is an objection that some countries are still reluctant to participate and address this crucial issue (Oberthur, 2001; Ulukan, 2009).

\section{Academic Use of Social Networking}

Social networking sites are theWeb 2.0 based applications that allow users to share personal information with each other in convenient ways. Social networking sites focus on building and reflecting on social relations and interactions among people who possess the same interests. Social network sites essentially represent individuals' profiles, social links and a variety of additional services. They enable users to share ideas, opinions, activities events, and interests within their individual networks over the Internet through e-mail and instant messaging. Facebook, Hi5, LinkedIn, MySpace, Nexopia, Twitter and YouTube are successful applications of social networking services. They emphasize online collaboration, social collaboration and resource sharing among users free of charge.

\subsection{Advanced Features of Social Networking Applications}

The Web 2.0 not only has additional features from its predecessor Web 1.0, traditionally known as Web technology, but it is also qualitatively different from the Web 1.0 in many ways. Web 2.0 enables its users to interact with other users actively (such as in chat rooms) and view information passively that is provided to them by its developer. The dynamic features of Web 2.0 allow its users to interact with other users actively, or to change website content interactively, interoperably and simultaneously. If Netscape is the standard bearer for Web 1.0, Google is the standard bearer for Web 2.0.

In the Web 2.0 platform everyone is both a consumer and a seller of information who defines and designs the contents of the Web. The interactive features of the Web 2.0 technology enable its users to actively participate and contribute to develop and enrich the Web page contents. Moreover, the Web 2.0 users will be able to create, share and enhance their knowledge and thinking with other users in the network. They will share knowledge and information wherever it is located and whenever it is needed through the Web.

Furthermore, the improved functionality of the Web 2.0 tools such as openness and freedom of control over data have made it exceptional when compared to the traditional Web development approach. This means that Web 2.0 tools allow users to add their own content with few or no restrictions at all. Web 2.0 allows its users not only to retrieve information but also encourages them to input additional resources into the application as they prefer.

On a Web 2.0 site, users can own data and can have control over that data (O'Reilly, 2005). A Web 2.0 site allows its users to interact with other users or to simultaneously change website content from any location, any time. In order to do this, Web 2.0 technology uses open source coding that means that the Web design codes are available for others to use and 
customize freely. It has caused the Web to shift from being a medium in which information is transmitted by a few and consumed by the rest, into being a platform where content is created, shared, remixed, repurposed, and passed along (Downes, 2005).

\section{Social Networks as Platforms for Awareness of Global Warming and Climate Change}

Social networking sites are the advanced technologies that facilitate sharing experiences with others either explicitly or anonymously. The interactive and read-write nature of the Web 2.0 technologies, such as Blogs, Facebook, Wikis, and Podcasts could facilitate users' participation and build rich and user-centered virtual communities that could attract more people to participate and interact in building many collaborative societies simultaneously (Alexander, 2006). By participating in such a virtual community, people can share their past and present experiences caused by environmental pollution and, global warming, free of charge. Thus, the Web 2.0 could be an appropriate technology to build many local and global virtual communities among people in different cultures to help them be aware of global warming and climate change.

Blogging is a Web 2.0 tool that has tremendous usage in building effective, interactive, and collaborative virtual platforms (Solomon \& Schrum, 2007). Based on the advanced and interactive features of Blogging technology, it could be an appropriate media to build many virtual intercultural platforms at home and abroad. Such intercultural platforms could bring people from diverse cultures and societies into a single platform to let them discuss about the possible effects of climate changes, and empower them to work against the environment pollution.

In the proposed project we would like to develop and maintain a Blog and a Facebook account where people from these diversified backgrounds and societies can discuss various contemporary issues about global climate change, and contribute their views for effective solutions. In line with intercultural education, this could bring up a new dimension in the environmental studies. However, to suggest any specific conclusions might be presumptuous at this time.

\section{Method}

The study was designed with the research question, "How can the interactive futures of social networking tools, such as Facebook and Twitter, be used to bring people from diverse societies and locations into a single platform to make them aware of climet change issues?" An intercultural platform was developed where participants from various locations throughout the World came together and expressed their experience and views on environmental pollution, global warming, and climate change issues. A Blog site and Facebook account were created to start online discussions.

The study was grounded in the field of qualitative research to collect data through the literature review and repetitive themes through the social networking accounts. As such, qualitative research involves an interpretive, naturalistic approach to understanding the world. According to Merriam (1998), "Qualitative investigators are interested in understanding the meanings people have constructed, that is, how they make sense of their world and the 
experiences they have in the world" (p. 6). Qualitative research is a tool used for understanding and describing the world of human experience (Myers, 2002). The qualitative approach, importantly, allows the researcher to gain deeper understanding of the phenomena under study through participations' experiences. Guba and Lincoln (1994) pose that qualitative research explains the why and how of human behavior, rather than focusing on numbers and statistics that try to explain only what it is that is taking place. Another significant strength of the qualitative approach is its potential for providing richness of exploration and description.

First, a snowballing sampling method was used to invite more participants in the activity. According to the features of snowballing approach and social networking technologies, once a number of participants will joined in the online discussion, other people who are in the network of the existing participants will be invited in the discussion. They were asked some general to specific questions regarding the effects of global climate change in their locality. Sample questions were as follows: How much do you know about and are aware of global climate change issues? What are the adverse effects of climate change in your area that you would like to present to the global community? Are you personally or generally affected by these adverse effects? How would you like to see these problems resolved or compensated?

Participants were purposefully assigned into Facebook account, such as self-selection through snowballing connections. Each participant will be given the opportunity to add to the list of possible participants. Then a few potential respondents were contacted and asked whether they know anybody who is personally affected by climate change issues that can give us valuable information in our study. Participants' responses were synthesized and analyzed through qualitative case study approach. Then, through the responses from participants, the researchers started search of "underlying meaning," as suggested by Creswell, (2003, p. 155), and the researchers compared responses from all participant across all platforms. Through the data analysis, the content analysis was used to find out themes and patterns for the research findings.

\section{Results}

The purpose of this study was to examine the consequences of developing climate change modules with social networking technologies in intercultural contexts. In addition, the study documents the potential of using Facebook technology by the secondary school students and teachers from different societies of the world to share their experiences about the global warming and climate change issues. A literature review with content analysis data was collected based on open-ended questions through the facebook users during the spring 2011 semester. Major findings of the study shows that (1) there are millions of people including secondary school students and teachers are using social networking applications such as Facebook, Twitter, hi5, MySpace to communicate their friends, families, and colleagues; (2) social networking sites have tremendous possibilities in developing many virtual communities in home and abroad to bring students, teachers, and educators from different corner of the world into a single virtual platform to work together on global warming and climate change issues; and (3) participants in such a virtual platform can motivate their friends, families, 
relatives, and colleagues to join or make such platforms and play active role in resolving or reducing many possible causes of environmental pollution, global warming, and climate change issues.

A good number of participants contributed in the study with their views and experience with climate change issues from their personal and local perspectives. This approach will be more useful than a study carried on a setting in which possible participants are scattered or not found in clusters (Snijders, 1992).

Although, the effects of global warming are not seen equally in every corner of the world, the adverse situations of global warming are mostly seen in the developing and underdeveloped countries. A number of countries that are very close to the sea level are very much concerned about global warming and have been asking developed countries to take initiatives so as to reduce the effects of greenhouse gases. These countries have brought climate change issues to the United Nations and other concerned agencies to protect them from the possible disasters related to global warming and climate change.

Consequently, the terms climate change and global warming have been considered as important issues worldwide, and have gotten attention by individuals, governments and non-government organizations worldwide. Individuals in these organizations are expecting a disaster or major change in nature and the environment in the very near future. Environmental scientists, politicians, legislators, and governments have been working in long-term projects and plans for reducing global warming and environmental pollution.

Thus, global warming and climate change have become important issues in the national and international intercultural forums, and demand to be expanded from top to bottom, especially among masses of people to make everybody be aware of these elements. Intercultural communication is a kind of global interaction that could be used for cross-cultural dialogue for global warming and climate change issues. It could prepare people living in diverse societies in the various corners of the world to become aware of the possible disasters of global warming and climate change, and help them work together against environmental pollution and global warming.

It is expected that there will be more benefits accrued by using Web 2.0 technology in building a virtual intercultural platform to help people be aware of the climate change. First, it can promote more collaboration among people from different cultures. Second, it may motivate young people to explore, discuss and share their views and suggestions for being aware on climate change and work against environmental pollution. Third, Web 2.0 based collaborative learning might also enable researchers, educators and legislators to disseminate their knowledge of new ideas to each other in ways that cannot take place without it. When an individual participant gets a different or interesting idea in his view, s/he may become more willing to continue further discussion or participate with other people or Blogs. This could be a good opportunity to more widely share information for first time researchers as well as general people whose voices and perspectives cannot be published in news media or refereed journals. As more people participate in online discussion on important climate change topics, and take the opportunity to express their voice on media, increased understanding in science topics might ensue. 
Finally, and probably the most important advantage of Web 2.0 based intercultural activities is that educators, especially, the K-12 science teachers, can motivate their students to participate in Blogging discussion during their leisure time outside the class period or school time. For students who have Internet access on their own or through their parents' computer or cellular devices, the Web 2.0 based discussion could take place anywhere, e.g., around the dining table, on the school bus, in a restaurant, or at a shopping mall. Participating children can motivate their parents and relatives to join in the discussion and play an active role in reducing environmental pollution. However, to suggest any specific conclusions might be presumptuous at this time.

\section{Implication}

Implication of the study shows that social networking based platform enable students, teachers, educators, researchers, and legislators to disseminate their knowledge of new ideas to each other in ways that cannot take place without it. When an individual participant gets a different or interesting idea in his view, they become more willing to continue further discussion or participate with other participants in the platform. That is an ideal opportunity to more widely share information for the young students and teachers whose voices and perspectives cannot be published in news media or refereed journals. As more participants join in the online discussion on important global warming and climate change topics, and take the opportunity to express their voice on media, increased understanding in science topics might ensue.

\section{Conclusion}

One of the best ways to initiate intercultural communication is by sharing one's own personal experiences with others. The Web 2.0 is such a technology that could be used to build many virtual societies where people from various corners of the world can come together and share their past and present experiences caused by environmental pollution, global warming, and climate change, free of charge. Based on the advanced and interactive features of Web 2.0 technologies, Blogging could be an appropriate medium to build many virtual intercultural platforms at home and abroad. Such intercultural platforms could bring people from diverse cultures and societies together in a single platform to let them discuss the possible effects of climate change, and enable them to work against environmental pollution.

\section{References}

Alexander, B. (2006). Web 2.0- A new wave of innovation for teaching and learning? Retrieved October 30, 2010, from http://net.educause.edu/ir/library/pdf/ERM0621.pdf Anonymous. (2010). Climate averages". Met Office. Retrieved October 28, 2011, http://www.metoffice.gov.uk/climate/uk/averages/

Bates, B., Kundzewicz, Z. W., Wu, S., \& Palutikof, L. (2008). Climate and Water. Technical Paper of the Intergovernmental Panel on Climate Change prepared for WMO and UNEF. Retrieved October 28, 2011, from http://www.ipcc.ch/pdf/technical-papers/climate-change-water-en.pdf 
Campbell, D. E. (1996). Choosing Democracy: A Practical Guide to Multicultural Education, Prentice-Hall, NJ.

Cruz, F. (2010). Developing Multiculturalism with Children in Schools: Analysis of Primary English Foreign Textbooks Contrasting to a Brazilian Textbook". The Journal of Multiculturalism in Education, 6(1), 1-18.

Downes, S. (2005, October). E-Learning 2.0. National Research Council of Canada Elearn Magazine, October 17, 2005. Retrieved November 10, 2009 from http://www.elearnmag.org/subpage.cfm?article=29-1\&section=articles

Guba, E.G. and Lincoln, Y.S. (1994). Competing Paradigms in Qualitative Research. In N.K. Denzin and Y.S. Lincoln (Eds.), Handbook of Qualitative Research (pp. 105-117). Thousand Oaks, CA: Sage Publications.

Houghton, J. T. (2001). Climate change 2001: the scientific basis: contribution of Working Group I to the Third Assessment Report of the Intergovernmental Panel on Climate Change. Cambridge, UK: Cambridge University Press.

Intergovernmental Panel on Climate Change [IPCC]. (2007). New Assessment Methods and the Characterisation of Future Conditions: In Climate change 2007: Impacts, adaptation and vulnerability, p: 976. Contribution of working group II to the fourth assessment report of the intergovernmental panel on climate change Cambridge university press, Cambridge, UK.

Martin, J. N., \& Nakayama, T. K. (2000). Intercultural communication in contexts. Mountain View, CA: Mayfield.

Nieto, S. (2004). Affirming diversity: The sociopolitical context of multicultural education, Pearson, Boston, MA.

Oberthur, S. (2001). Linkages between the Montreal and Kyoto protocols enhancing synergies between protecting the ozone layer and the global climate. International Environmental Agreements, 1, 357-377.

O'Reilly, T. (2005). What is Web 2.0: Design patterns and business models for the next generation of software. Retrieved February 16, 2010, from http://www.oreillynet.com/pub/a/oreilly/tim/news/2005/09/30/what-is-web-20.html

Richardson, W. (2006). Blogs, wikis, podcasts, and other powerful web tools for classrooms. Thousand Oaks, CA: Corwin.

Snijders, T. A. B. (1992). Estimation of the Basis of Snowball Samples: How to Weight? Bulletin de Methodologie Sociologie, 36 (9), 59-70.

Solomon, G., \& Schrum, L. (2007). Web 2.0 new tools, new schools. International Society for Technology in Education, Washington, DC.

Ulukan, H. (2011). Responses of cultivated plants and some preventive measures against climate change. International Journal of Agriculture and Biology, 13, 292-296

United States National Academy of Sciences [USNAS]. (2008). Understanding and Responding to Climate Change. http://americasclimatechoices.org/climate_change_2008_final.pdf

Wikipedia. (2011). Climate. Retrieved from http://en.wikipedia.org/wiki/Climate 